\title{
DOS AMARAIS AOS TERRA CAMBARÁS: PODER, CONFLITO E MEMÓRIA EM O TEMPO E O VENTO
}

\author{
Francisco Mateus Conceição'
}

\begin{abstract}
Resumo: Ao longo da história de $O$ Continente narra-se a origem e a ascensão social da família Terra Cambará. Tal ascensão ocorrerá através do casamento de Bolívar com Luzia, de maneira que da origem até essa geração, a família fará parte da periferia do poder exercido pelos Amarais. Por isso, há uma clivagem social fortemente marcada na parte inicial da obra. No tocante a isso, os momentos de maior tensão provavelmente estejam no capítulo Um Certo Capitão Rodrigo. Nitidamente, há, nessa parte da narrativa, um conflito social, sendo que a família Amaral representa o poder econômico e político, enquanto Rodrigo e Juvenal pontificam a voz dos socialmente excluídos. Esse conflito se dá, também, no terreno da memória. Inicialmente, a versão oficial dela é controlada pela família Amaral, mas, ao mesmo tempo, a sua contraposição é repetida, furtivamente, pela "massa do povo", os homens e mulheres que estão sob o comando dessa família. Com a ascensão dos Terra Cambarás, a tensão social parece evanescer na sequência da trilogia. Pretendemos demonstrar que, diferentemente dos Amarais, aqueles utilizarão também da sedução para se manter no poder, caracterizando-se, através do Dr. Rodrigo, o que Roberto Schwarcz denomina "dialética do favor".
\end{abstract}

Palavras-Chave: Poder. Opressão. Memória. Favor.

Abstract: Along the story of $O$ Continente, it is narrated the rise and fall of the family Terra Cambará. Such rise will occur through Bolivar and Luzia's marriage in a way that, from the origin to the present generation, the family will belong to the fringes of the Amarais' power. Consequently, there is a well-marked social division in the first part of the novel. Considering such feature, there are moments of high tension in Um certo Capitão Rodrigo's chapter. Understandably, it is perceived in this part of the narrative the presence of social conflicts, in other words, while the Amaral represents political and economic power, Rodrigo and Juvenal highlight the presence of minority voices. This conflict also deals with memory issues. At the beginning, its official version is controlled by the Amaral, but, at the same time, its opposite version is repeated by common people, men and women that are under the control of that family. By the rise of the Terra Cambarás, social tension may appear in the sequence of the trilogy. In this regard, the present paper attempts to demonstrate that different from the Amarais, the other family will also use seduction to keep power control, characterizing themselves, through Dr. Rodrigo's portrayal, what Roberto Schwarcz named as "dialetics of favor".

Keywords: Power. Oppression. Memory. Favor.

1 Doutorando em Estudos Literários no Programa de Pós-Graduação em Letras na UFSM.
Orientadora Prof.- Dr. - Rosani Ketzer Umbach. E-mail: fmfranciscomateus@gmail.com 
Em O Tempo e o Vento contrapõem-se perspectivas diferentes frente à história. Sob o viés social, pode-se dizer que, à história dos que detém o poder, a narrativa contrapõe a visão dos que dele são excluídos, o que se pode chamar de a "história vista de baixo". Conforme Jim Sharpe, tal perspectiva se opõe à visão tradicional, que narra "os feitos dos grandes", passando a tratar como fonte de informação a "massa do povo" ou "aqueles homens e mulheres, cuja existência é tão frequentemente ignorada, tacitamente aceita ou mencionada apenas de passagem na principal corrente da história" (Sharpe, 1992, p. 41).

$\mathrm{Na}$ primeira parte da obra, $\mathrm{O}$ Continente, narra-se a origem e a ascensão social da família Terra Cambará, período em que há uma clivagem social claramente marcada.

Exemplo disto é a primeira convocação de Pedro Terra para tomar parte de uma guerra. Temerosa pelo filho, Ana solicita a Ricardo Amaral que o dispense, arguindo que estava com casamento agendado. O coronel, porém, não apenas negou o pedido como o ridicularizou, dizendo que o desejo mesmo de Pedro era "dormir com a moça". Sugere que o faça antes de partir, e que poderia casar depois, se retornasse vivo e ainda quisesse. Ana Terra será redimida, de certa forma, porque seu filho voltará com vida enquanto Ricardo Amaral perecerá no combate, e Chico Amaral (o filho mais velho) perderá um olho. Os Amarais, no entanto, aumentam o prestígio político, garantia de manutenção e ampliação de suas propriedades, motivo principal de sua participação nos combates. Sobre os membros de sua família correrão narrativas edificantes, em que despontam como heróis. Já os trabalhadores e suas famílias somente têm a perder com a guerra. E quando um deles morre não há indenização e sequer registro: apenas o silêncio. Como se percebe no momento em que os familiares vão encontrar os soldados que retornavam da guerra:

Tinham ficado enterrados em território castelhano quinze escravos, quatro peões e oito rancheiros. Os homens apearam dos cavalos, abraçaram os parentes e amigos e encaminharam-se para seus ranchos. E as mulheres cujos maridos, filhos, irmãos ou noivos não tinham voltado ficavam ainda um instante, meio estupidificadas, a esperar por eles debaixo da grande figueira. Mas de repente, compreendendo tudo, rompiam o choro. (Verissimo, 2005, p. 182) 
Essa polarização social se tornará mais explícita no capítulo intitulado Um Certo Capitão Rodrigo, quando Rodrigo e Juvenal pontificarão a voz dos socialmente excluídos. Observemos fragmentos de diálogo entre Rodrigo e o Pe. Lara:

- Me lembrei do coronel Amaral.

- E que é que ele tem a ver com nossa conversa?

- Tem muito. Ele é um leão baio. E dos grandes! E vosmecê parece ser mais do lado dele que do lado das ovelhas, padre.

O pe. Lara empertigou-se sobre a banqueta.

- Não compreendo - disse. Mas compreendia perfeitamente o que o outro insinuava.

- Vosmecê sabe como ele trata os escravos... - continuou Rodrigo. Para ele negro não merece ser considerado gente. Vosmecê sabe como ele trata os peões e agregados. E vosmecê não ignora que ele tem mandado matar gente... (Verissimo, 2005, p. 310)

Rodrigo encarna, nesse momento, a voz coletiva, expressando o que se comenta longe da família Amaral. O duelo que travará com Bento Amaral por causa de Bibiana tem esse componente de fundo. Componente que é verbalizado quando Juvenal intervém e denuncia a opressão e a violência que essa família exerce sobre a população de Santa Fé. Depois de citar alguns casos de pessoas que foram executadas a mando dos Amarais, conclui:

Todo mundo aqui tem medo dos Amarais. Pois eu, se tive algum, agora perdi. (...) Hai anos que a gente vive aqui encilhado pelos Amarais. O velho Ricardo Amaral tirou a terra do meu pai. Botou a corda no pescoço do coitado, quando ele ficou mal de negócios. Todo mundo sabe que a maior parte dos campos que esse velho tem foi roubada. (Verissimo, 2005, p. 376)

As injustiças praticadas pelos Amarais estão vivas e acumuladas na memória de Juvenal, que as refere de maneira explosiva. A característica desse ódio é percebida pelo Pe. Lara:

E o padre ficou surpreendido ao perceber no rosto do filho de Pedro Terra uma expressão que só podia ser ódio mal contido: uma surda raiva velava-Ihe a voz. E o vigário pela primeira vez percebeu como Juvenal detestava Bento Amaral. (Verissimo, 2005, p. 274)

Veja-se que Juvenal é nomeado na primeira frase como o "filho de Pedro 
Terra”. Não era apenas o personagem Juvenal que causava espanto ao padre, mas, principalmente, o membro da família Terra, na qual não se imaginava capacidade de guardar tanto ódio. Efetivamente, o padre estava equivocado, pois Pedro Terra cultivava rancor antigo contra os Amarais. Ódio que remontava à sua juventude, como se percebe no ato em que Chico Amaral, montado em seu cavalo, anuncia a edificação do povoado de Santa Fé:

Ana Terra escutava, mal entendendo o sentido daquelas frases. Pedro estava muito atento. Pensava no terreno que lhe ia tocar, e ao mesmo tempo olhava fascinado para as grandes botas do estancieiro, lembrando-se das botas do coronel Ricardo; ainda sentia por elas um secreto temor, que no fundo era surda malquerença. (Verissimo, 2005, p. 185)

Sua "malquerença" contribuirá para que não insista no casamento da filha com Bento. Além disso, chegará a se insubordinar contra os Amarais quando, às vésperas da Revolução Farroupilha, o coronel Ricardo exigir que a Câmara Municipal faça uma declaração de fidelidade ao governo. Pedro Terra posiciona-se contra o ato, o que lhe valerá uma sentença de prisão por parte do mandatário local.

Os episódios de enfrentamento são exceções que não têm a condição de alterar o curso da história. Nem por isso são menos importantes, pois estabelecem um contraponto à versão oficial, tensionando a narrativa. Além disso, sugerem e ajudam a sustentar uma memória maior, que é cultivada entre as gerações. Trata-se da visão desconfiada e resistente em relação ao domínio exercido pelos Amarais, visão esta que, sob uma perspectiva benjaminiana, fornece material para que se possa "escovar a história a contrapelo" (Benjamin, 1985, p. 225).

Com a ascensão social dos Terra Cambarás, há uma mudança na perspectiva narrativa. O poder antes visto de fora passará a ser investigado também por dentro. Além disso, os Terra Cambarás, sob a liderança do Dr. Rodrigo, aliam à força o recurso da sedução. Para melhor dimensionar esse procedimento, nos valemos do conceito de favor, como desenvolvido por Roberto Schwarz. Ao estudar o Brasil do século XIX, especialmente, a obra de Machado de Assis, o autor identifica no favor o parâmetro para explicar a 
relação das elites brasileiras com as classes sociais intermediárias. Conforme Schwarz:

com mil formas e nomes, o favor atravessou e afetou no conjunto a existência nacional, ressalvada sempre a relação produtiva de base, esta assegurada pela força. Esteve presente por toda parte, combinando-se às mais variadas atividades, mais e menos afins dele, como administração, política, indústria, comércio, vida urbana, Corte, etc. Mesmo profissões liberais, como a medicina, ou qualificações operárias, como a tipografia, que, na acepção européia, não deviam nada a ninguém, entre nós eram governadas por ele. (1988, p. 16)

Através das relações de favor, a elite mantinha as classes intermediárias sob seu controle, estabelecendo-se aí uma relação de troca. Desta forma, adaptava-se e desfigurava-se o processo de modernização em curso na Europa:

No processo de sua afirmação histórica, a civilização burguesa postulara a autonomia da pessoa, a universalidade da lei, a cultura desinteressada, a remuneração objetiva, a ética do trabalho etc. contra as prerrogativas do Ancien Régime. O favor, ponto por ponto, pratica a dependência da pessoa, a exceção à regra, a cultura interessada, remuneração e serviços pessoais. (Schwarz, 1988, p. 16)

Neste cenário, a Europa atua como referência cultural para a elite brasileira, que procura estar atualizada quanto às transformações que lá ocorrem. No entanto, como aqui não existem, também, transformações equivalentes na ordem social, as ideias importadas tornam-se marcadamente exteriores e ornamentais. Tal problema extrapola a realidade do século XIX e "iria repetir-se no séc. XX, quando por várias vezes juramos, crentes de nossa modernidade, segundo as ideologias mais rotas da cena mundial" (Schwarz, 1988, p. 19).

Ao retornar para Santa Fé com o diploma de médico, Rodrigo Cambará traz, além de equipamentos para montar o consultório médico, muitos livros (principalmente brasileiros, portugueses e franceses), um gramofone, chapas musicais, vinhos finos, champagne, perfumes, sapatos, roupas modernas... Trouxe o conhecimento que adquirira dessa cultura, e que passara a constituí-lo; sua imagem de homem moderno, dentre os Cambarás, " 0 
primeiro a vestir um smoking e a ler e falar francês". (Verissimo, 1951, p. 64). Com ele veio o apuro da imagem, que envolvia longo tempo de preparação antes de sair à rua, característica que o comparava a um dandy. Tudo isso o distingue frente aos demais habitantes do lugar, e Rodrigo sabe fazer uso da cultura moderna sem negar a tradicional. Continua frequentando a estância e até se exercita na lida campeira, para não perder o respeito dos peões. Conversa e é afável com todos e, na cidade, chega a tomar café novamente, para agradar ao dono da padaria. Torna-se, portanto, um homem carismático e sedutor.

$\mathrm{Na}$ vida pessoal, revela-se generoso e preocupado em ajudar os mais próximos a ascender economicamente. É o que se percebe com Dante Camerino, um engraxate em quem percebe talento para o estudo e ao qual acaba pagando o curso de medicina. O apadrinhado se estabelecerá como médico, sendo, inclusive, quem acompanhará a saúde de Rodrigo nos seus últimos dias. O mesmo sucesso, porém, não se repetiu com Arão Stein. Sustentado e praticamente empurrado por Rodrigo, estudou por quatro anos, no Ginásio Anchieta, em Porto Alegre. Mas quando iria cursar o primeiro ano de Medicina, Ihe falece o pai e ele retorna a Santa Fé com o objetivo de cuidar da mãe e de um ferro-velho, que era a forma de sustentação da família. Frente à decepção do protetor, responde que este talvez seja o seu destino. Anos depois, já entusiasmado com o ideal comunista, esquecerá o citado destino e irá lutar na guerra civil espanhola, abandonando a mãe, que acabará falecendo. A contradição entre esses dois momentos demonstra que, embora tenha aceitado a ajuda de Rodrigo, não se sentia muito à vontade com ela, motivo que talvez tenha soado mais forte para desistir do curso de medicina.

A bonomia de Rodrigo também se revela em relação à Sílvia. Ela é filha de uma modista e perdera o pai ainda na infância. Afilhada de Rodrigo se torna amiga de seus filhos e frequenta diariamente o Sobrado. Em seu diário, ela recorda que, certa feita, o padrinho ajudou sua mãe, "com dinheiro, cuidados médicos e medicamentos." (Verissimo, 2004, p. 338). Além disso, pagou seus estudos na Escola Normal. Obviamente, Sílvia era encantada com Rodrigo, encanto extensivo à vida no Sobrado, mas sua mãe "recebia mal todos esses favores" (Verissimo, 2004, p. 338), como recorda a filha: "Sempre 
que Alicinha me dava um de seus vestidos ou um par de sapatos já usados, mamãe olhava para essas coisas e murmurava: 'É triste a gente viver das sobras dos ricos"” (Verissimo, 2004, p.338).

Rodrigo sente-se à vontade no exercício de seu papel, colhendo os frutos daqueles a quem favorece, através da admiração e do respeito. Assim, a prática do favor mantém e até reforça a hierarquia social. Por isso, o que incomoda a mãe de Sílvia na ajuda de Rodrigo é que esta se constitui em mais uma manifestação de seu poder. Juntamente com o favor, impõe-se e legitimase sua ascendência sobre os demais. É por isso que a modista apenas conseguia murmurar seu descontentamento e que Arão Stein valeu-se da figura da mãe para rejeitar auxílio. Além disso, o favor age no sentido de atrair o favorecido para a órbita de quem o ajuda. O caso de Sílvia é emblemático porque ela parece ser, desde criança, um personagem do Sobrado, mesmo que ocupe nele um posto inferiorizado. Seu casamento com Jango, estimulado por Rodrigo, sacramenta e define a passagem para a família Terra Cambará. De maneira que o "Caderno de Sílvia" cumpre, entre outras, a função de recuperar seu lugar e sua voz.

A prática do favor não exclui o recurso da força, utilizada quando a sedução não se mostra eficaz. Ao assumir a função de intendente municipal, Rodrigo lança-se em busca de doações junto aos empresários para resolver o dilema das moradias miseráveis. Porém, ao inaugurar o primeiro lote de novas residências, uma das famílias previstas para ocupá-las nega-se a mudar-se do lugar em que mora. Ao ver que seus argumentos são infrutíferos e que os moradores estão obstinados em ali permanecer, como se sua obra não tivesse valor algum, o mandatário local utiliza-se de um expediente arbitrário e violento: ordena a um funcionário que ateie fogo ao barraco. Veja-se fragmento do relato desse episódio, sob o viés memorialístico de Rodrigo, em diálogo com o filho Floriano:

Ao ver o rancho em chamas, a família rompeu a gemer e a chorar, o Juca Cristo caiu de joelhos, ergueu os braços como um profeta e começou a gritar coisas para o céu. Me amaldiçoou, me rogou pragas, disse horrores... Eu já não sabia se lhe pedia desculpas ou se Ihe dava um pontapé na cara. A mulher, essa parecia uma possessa, atirada no chão, rolava no barro, soltando guinchos. E os olhos daquelas crianças... Santo Deus! Estavam fitos em mim com uma expressão de pavor como se eu fosse um monstro, um incendiário! Aí 
tens outra prova de que o povo não sabe bem o que lhe convém. (Verissimo, 1976, p. 574)

O que move, ideologicamente, Rodrigo é a preocupação humanitária e a obsessão pelo progresso. No entanto, percebe-se que, ao lançar mão da violência já não são mais esses componentes que estão em primeiro plano, mas o orgulho ferido do "senhor do sobrado", que "ali estava, furioso e ao mesmo tempo embaraçado, recendente a Chantecler, metido no seu sobretudo com gola de astracã”. (Verissimo, 1976, p. 574)

Como se percebe, renovam-se as formas de exercício de poder, que continua, ainda, sob o controle da mesma classe social. Pode-se afirmar que a sua imposição adquire, conforme 0 andamento da narrativa, maior dissimulação e complexidade. Por esse motivo, a tensão social tende a diminuir conforme a história avança. Ainda assim, o conflito de perspectivas continua estruturalmente presente no romance.

\section{REFERÊNCIAS}

BENJAMIN, Walter. Magia e técnica, arte e política: ensaio sobre literatura e história da cultura. Tradução de Sérgio Paulo Rouanet. 3. ed. São Paulo: Brasiliense, 1987. (Obras escolhidas, Vol. 1).

SCHWARZ, Roberto. Ao vencedor as batatas. 3. ed. São Paulo: Duas Cidades, 1988.

SHARPE, Jim. A história vista de baixo. IN: BURKE, Peter (Org.). A escrita da história: novas perspectivas. São Paulo: UNESP, 1992.

VERISSIMO, Erico. O tempo e o vento I: o Continente I. São Paulo: Companhia das Letras, 2005.

O Continente. 26. ed. São Paulo: Globo, 1995.

O tempo e o vento II: o retrato. Porto Alegre: Globo, 1951.

1976. Vol. 2.

O tempo e o vento III: o arquipélago. 4. ed. Porto Alegre: Globo,

. O tempo o vento III: O arquipélago, vol. 3. São Paulo: Companhia das Letras, 2004. Vol. 3. 